the non-attenders at clinics and their reasons, or to follow up cases that should have been referred from hospitals. Because conditions are bad the health visitor staff is continually changing.

A good health visitor (they are better than "public health nurses," because they have some midwifery and are better able to deal with family situations) is a truly wonderful person. She is able to sense the situation before the baby gets battered. She can advise about the control of cockroaches one day, on granny's enema on another, and on the behaviour of the teenage daughter on yet another. The fact is her approach through practical, physical factors makes her acceptable. She is not associated with any particular detrimental situation. She can provide a routine, continuing source of supervision and support, and can call in experts in special fields as needed. Not all health visitors are angels. Some have been preconditioned by hospital training where nurses are too authoritarian to their patients and to their juniors, and too subservient to their seniors. Others take up the work mainly because of regular hours and living at home. In the present tragic state of health-visitor shortage some who are unsuitable or who need more postgraduate experience and supervision are employed for lack of better personnel.

The value of domiciliary work has been proved repeatedly and in many countries. The doctors who have been trained almost entirely in institutions have very little concept of how much they have to learn and to give when the domiciliary and family conditions are appreciated. The present increase and popularity of social workers is of course bound to happen in a country where statistics show a great improvement in health and longevity. Many of the existing problems are now those of behaviour and responsibility, some of them created by permissiveness and the Welfare State.

The training of assistantes sociales in France has much to recommend it. The fact that they all receive a basic year or two in hospital is a good starting-point, though I must admit that some of the subsequent training and use of these workers is wasteful. The present situation, both in the rich and in the poor countries, calls for great expansion and improvement in the health-nurse and home-nurse services. This is the policy that would lead to the greatest improvement in health-physical, mental, and social-and economies in medical manpower and hospital facilities. The situation calls for a more realistic approach by doctors, politicians, and administrators.-I am, etc.,

London S.E.24. Cicely D. Williams

\section{Malabsorption and Surgery}

SIR,-In his helpful and interesting contribution Mr. C. Wastell (14 September, p. 661) omitted to mention other watersoluble vitamins of the $B$ group. These are normally absorbed in the duodenum and upper jejunum, which may be chronically inflamed in association with peptic ulcer, for which total gastrectomy or extensive resection of the stomach may be undertaken. I have seen pellagra following such operations in several patients, in some of whom it may be necessary to give the vitamin supplements parenterally, and in this respect these patients resemble the chronic alcoholic, in whom oral administration of full vitamin supplement fails to prevent pellagra. It is of interest, too, that in Britain pellagra tends to be more florid in exceptionally sunny summers such as 1949 and 1959.-I am, etc.

\section{Department of Dermatology,}

E. J. Moynahan.

\section{Guy's Hospital.
London S.E.1.}

\section{Plasma Volume in Macroglobulinaemia}

SIR,-We were interested to read the discussion of a case of macroglobulinaemia in the clinicopathological conference (27 July, p. 237).

There may be some relevance in observations we made on the following case of a man whose illness we followed for four years prior to his death in 1964 at the age of 46 years. The clinical pattern approximated most closely to the group of macroglobulinaemia associated with a cold agglutination syndrome. Cold haemolysins had been first noted in 1950. The level of plasma globulin rose from $3.0 \mathrm{~g}$. to over $7.5 \mathrm{~g} .1100 \mathrm{ml}$ between 1960 and 1964 . Electrophoresis revealed a compact band in the gammaglobulin area, and immunoelectrophoresis showed a very large increase of $r M\left(\beta_{2} M\right)$ macroglobulin (Dr. J. Kohn). An unusual feature of the terminal 18 months of his illness was intractable headache, which led us to measure his blood volume. In August 1964 the following results were obtained:

Plasma Volume

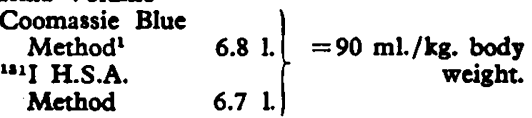

Red Cell Volume

(By calculation from venous P.C.V.) 2.01 . = $26.5 \mathrm{ml} / \mathrm{kg}$ body weight.

(Ranges of plasma and red cell volume for normal adult males are $43.6 \pm 5.79$ and $30.1 \pm 5.74 \mathrm{ml}$. per kg. body weight respectively." Our patient weighed $75 \mathrm{~kg}$.)

At this time his haemoglobin level was $5.7 \mathrm{~g} . / 100 \mathrm{ml}$. and the packed cell volume $22 \%$, and it is evident that increased plasma volume was mainly responsible for these marked reductions. These findings indicated that the total amount of circulating globulin was over 500 g., or, using the estimate of Gabuzda, a total body pool of approximately $750 \mathrm{~g}$. at the serum globulin level of $7.5 \mathrm{~g}$. $100 \mathrm{ml}$. The histological findings in the case were lymphocytoid infiltration of the marrow. Death was due to cerebral haemorrhage as a part of a generalized haemorrhagic diathesis developing one month after the blood volume studies. Post-mortem histology did not add to the known pathology of the case.

We wish to raise the possibility of a plasmaexpanding effect of massive globulinaemia. Hobbs ${ }^{4}$ based his calculations on an arbitrar plasma volume of $60 \mathrm{ml} . / \mathrm{kg}$. body weight, purposely high to make allowance for the anaemia which was common in his series. Actual measurements of the plasma volume in macroglobulinaemia appear to have been few. Our data would suggest that the use of an arbitrary plasma volume in calculations of protein pools relevant to the rate of evolution of gammopathies could be quite misleading. Furthermore, a knowledge of actual alterations in plasma volume may help to clarify certain clinical problems such as the need for transfusion or plasmapheresis, and the response to cytotoxic therapy.We are, etc.,

St. Helier Hospital,

St. Thomas's Hoondit

\section{REPERENCBS}

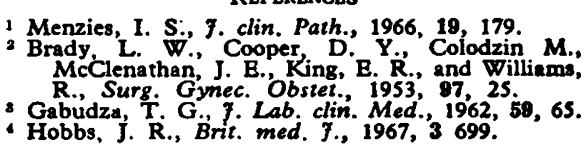

\section{Cancer and Asbestos}

SIR,-Your leading article on "Cancer and Asbestos" (24 August, p. 448) drew attention to the rise in the percentage incidence of intrathoracic malignancy in males dying with asbestosis in Great Britain from 19.7 in $1924-40$ to 54.5 in 1961-3. It was also noted that the mean age at death in cases of malignancy associated with asbestosis "remained almost constant between 54.3 and 57.6 years" over the period 1924 63. ${ }^{2}$ Over this same period the number of cases, in males, dying with intrathoracic malignancy in England and Wales rose persistently and this malignancy formed an increasing proportion of deaths from all causes especially within the age groups between 50 and 64 years. ${ }^{2}$ The increase in the percentage incidence of intrathoracic malignancy in asbestotics between 1924 and 1963 might be due in some measure to the increased incidence of this cause of death in the general male population of England and Wales surviving beyond the age of 50 years, and in part to a change in the incidence of intrathoracic malignancy in the asbestotic population.

Examination of copies of the death certificates, of males dying with asbestosis, held by the Factory Department of the Ministry of Labour showed that between 1931 and 1965 (both years inclusive) there were 452 certificates relating to men who had died between the ages of 30 and 79 years. The deaths in each calendar year were divided into five-year age groups from 30-34 years to 75-79 years, and, from the appropriate data in the annual Statistical Reviews, ${ }^{2}$ the number of expected deaths from intrathoracic malignancy was calculated for each age group. It was thus possible to arrive at an estimate of the number of deaths from intrathoracic malignancy to be expected in successive time periods. The numbers of expected and observed deaths from intrathoracic malignancy associated with asbestosis for these time periods are shown in the Table

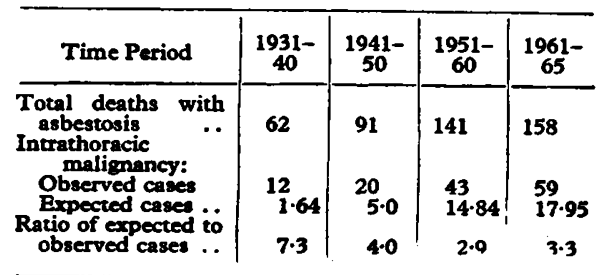

In each time period there was an excess of observed deaths over the expected deaths. 